\title{
Flow diversion in the treatment of aneurysms: a randomized care trial and registry
}

\author{
Jean Raymond, MD, Jean-Christophe Gentric, MD, ${ }^{1,2}$ Tim E. Darsaut, MD, ${ }^{3}$ Daniela lancu, MD, ${ }^{4}$ \\ Miguel Chagnon, MSc, ${ }^{5}$ Alain Weill, MD, ${ }^{1}$ and Daniel Roy, MD'

\begin{abstract}
1'Department of Radiology, Centre Hospitalier de l'Université de Montréal, Notre-Dame Hospital, Montreal, Quebec, Canada; ${ }^{2}$ Groupe d'Étude de la Thrombose en Bretagne Occidentale, Brest, France; ' ${ }^{2}$ ivision of Neurosurgery, Department of Surgery, University of Alberta Hospital, Mackenzie Health Sciences Centre, Edmonton, Alberta, Canada; ${ }^{4}$ Department of Radiology, Ottawa Hospital, Civic Campus, Ottawa, Ontario, Canada; and ${ }^{5}$ Department of Mathematics and Statistics, Université de Montréal, Quebec, Canada
\end{abstract}

OBJECTIVE The Flow Diversion in the Treatment of Intracranial Aneurysm Trial (FIAT) was designed to guide the clinical use of flow diversion, an innovative method to treat intracranial aneurysms, within a care trial and to study safety and efficacy.

METHODS FIAT, conducted in 3 Canadian hospitals, proposed randomized allocation to flow diversion or standard management options (observation, coil embolization, parent vessel occlusion, or clip placement), and a registry of nonrandomized patients treated with flow diversion. The primary safety outcome was death or dependency (modified Rankin Scale score $>2$ ) at 3 months, to be determined for all patients who received flow diversion at any time. The primary efficacy outcome was angiographic occlusion at 3-12 months combined with an independent clinical outcome.

RESULTS Of 112 participating patients recruited between May 2, 2011, and February 25, 2015, 78 were randomized (39 in each arm), and 34 received flow diversion within the registry. The study was halted due to safety concerns. Twelve $(16 \%)$ of 75 patients $(95 \% \mathrm{Cl} 8.9 \%-26.7 \%)$ who were allocated to or received flow diversion at any time were dead $(n=$ 8 ) or dependent $(n=4)$ at 3 months or more, crossing a predefined safety boundary. Death or dependency occurred in 5 $(13.2 \%)$ of 38 patients randomly allocated and treated by flow diversion (95\% $\mathrm{Cl} 5.0 \%-28.9 \%)$ and in $5(12.8 \%)$ of 39 patients allocated to standard treatment $(95 \% \mathrm{Cl} 4.8 \%-28.2 \%)$. Efficacy was below expectations of the trial hypothesis: 16 $(42.1 \%)$ of 38 patients $(95 \% \mathrm{Cl} 26.7 \%-59.1 \%)$ randomly allocated to flow diversion failed to reach the primary outcome, as compared with 14 (35.9\%) of 39 patients allocated to standard treatment (95\% Cl $21.7 \%-52.9 \%)$.

CONCLUSIONS Flow diversion was not as safe and effective as hypothesized. More randomized trials are needed to determine the role of flow diversion in the management of aneurysms.

Clinical trial registration no.: NCT01349582 (clinicaltrials.gov)

https://thejns.org/doi/abs/10.3171/2016.4.JNS152662

KEY WORDS aneurysm; flow diversion; flow diverter; clinical trial; vascular disorders

$\mathrm{F}$ Low diversion is a new endovascular treatment of intracranial aneurysms. ${ }^{1,3}$ Unlike coil embolization, in which the goal is to occlude the aneurysm sac, treatment with flow diversion attempts to normalize arterial flow and repair the vessel bearing the aneurysm. Flow diverters have been approved for the treatment of large and giant aneurysms of the cavernous to superior hypophyseal segments of the carotid artery, but usage has expanded to other difficult aneurysms, and more recently to small aneurysms treatable by other means. ${ }^{6,13,16,19,21,25,33}$ Systematic reviews of case series and registries have shown occlusion rates exceeding $75 \% .^{1,3}$ There is poor agreement regarding

ABBREVIATIONS BSO = best standard option; $\mathrm{Cl}=$ confidence interval; $\mathrm{DSMC}=$ Data Safety and Monitoring Committee; FIAT = Flow Diversion in the Treatment of Intracranial Aneurysm Trial; $m R S=$ modified Rankin Scale; $P V O=$ parent vessel occlusion.

ACCOMPANYING EDITORIAL See pp 449-453. DOI: 10.3171/2016.5.JNS161096.

SUBMITTED November 17, 2015. ACCEPTED April 27, 2016.

INCLUDE WHEN CITING Published online November 4, 2016; DOI: 10.3171/2016.4.JNS152662. 
indications for flow diversion; ${ }^{8}$ the role that flow diversion should play in clinical practice remains unclear. ${ }^{4,11,20,26,28,31}$ Nonrandomized comparisons of flow diversion with coil embolization have shown promising results, but a randomized trial has not been reported. , $^{74}$

The purpose of the Flow Diversion in the Treatment of Intracranial Aneurysm Trial (FIAT) was to provide a clinical trial context for the use of flow diversion in the care of patients with difficult intracranial aneurysms. FIAT proposed randomized allocation to flow diversion or standard management options, and a registry of flowdiverted patients considered ineligible for standard management options. ${ }^{23}$ The main hypothesis of the pivotal trial was that treatment with flow diversion, compared with other management options, would increase the proportion of patients reaching the primary outcome, which was occlusion or near-occlusion of the aneurysm combined with an independent clinical outcome (modified Rankin Scale [mRS] score $>2$ ).

\section{Methods}

FIAT was an investigator-led, simple, pragmatic, multicenter randomized controlled care trial integrated into clinical practice. ${ }^{22}$ FIAT compared a policy of using either flow diversion (any device, with or without coil embolization) or best standard treatment to manage patients with intracranial aneurysms. Standard treatment was selected according to clinical judgment at the time of enrollment but prior to randomization. Patients deemed ineligible for other management alternatives were included in a parallel registry. There were 3 Canadian centers that participated in the study: Notre Dame Hospital of the Centre Hospitalier de l'Université de Montréal, the Ottawa Hospital, and the Mackenzie Health Sciences Centre of the University of Alberta Hospital. All sites received Institutional Review Board approval. The protocol was published, ${ }^{23}$ and the trial registered with the US NIH (clinicaltrials.gov no. NCT01349582).

\section{Study Population}

All patients harboring an aneurysm for which flow diversion was considered a promising treatment were eligible to participate. There were few exclusion criteria: 1) severe allergy, intolerance, or bleeding disorder that precluded dual antiplatelet regimens; 2) absolute contraindication to endovascular treatment or anesthesia; or 3) inability to provide consent. All patients signed an informed consent form.

\section{Randomization and Masking}

Concealment of randomized allocation (ratio 1:1) was ensured through a web-based platform. Treating physicians had to first choose, according to clinical judgment and for each patient, 1 of 5 alternatives to permit computer-generated randomization or not $(1=$ coiling [with or without stenting], 2 = parent vessel occlusion (PVO), 3 = surgical clipping, $4=$ conservative management) or "none (registry for compassionate use)." A minimization algorithm was used to balance groups according to comparator intervention and center. Patients, interventionists, and outcome assessors were not blinded to treatment assignment.

\section{Interventions}

There were no selection criteria for centers, but all participating operators had performed at least 10 flow diversion cases. Standard local procedures were followed. Any arterial (not intraaneurysmal) flow-diverting devices were permitted. Testing for platelet inhibition was not required per protocol; antiplatelet and anticoagulation regimens were prescribed according to routine practice at each site. Follow-up tests and visits, judged to be clinically indicated, included neurological examinations, brain imaging studies, and a functional assessment according to the mRS score at discharge, 1 month, and 3-12 months, and angiography (invasive or noninvasive) at 3-12 months. Data capture and management were completed through secure servers (MedSciNet) in compliance with good clinical practice requirements. Case report forms were simple, and data were collected parsimoniously, to facilitate completion by normal care personnel. No financial compensation was provided to participating centers.

\section{Hypotheses and Outcomes}

FIAT included a pilot and a pivotal phase. The hypothesis of the pilot phase was that flow diversion could be performed safely, defined in terms of the mRS scale at 3 months: "200 patients could suffice to show that, if the observed number of patients with $\mathrm{mRS}>2$ is $10 \%$, the $95 \%$ CI of the proportion is from $7.0 \%$ to $14.9 \%$." ${ }^{23}$ The pivotal phase (250 randomized patients) was powered to show an increase (from $75 \%$ to $90 \%$ ) in the proportion of patients reaching the composite primary efficacy outcome, i.e., the complete or near-complete occlusion of the aneurysm (312 months) combined with an independent functional outcome (mRS score $\leq 2)$. Clinical outcome was determined by attending clinicians not blinded to treatment allocation according to the mRS.

Secondary outcomes included the mRS score at discharge, and 3 and 12 months posttreatment; the success in occluding the aneurysm at the end of the procedure (when appropriate); perioperative complications (ischemic strokes and intracranial hemorrhages); angiographic outcome (invasive or noninvasive imaging) results at 3 and 12 months; length of hospital stay (number of days); discharge disposition (home, other hospital, rehabilitation facility, or death); any new stroke, neurological symptom or sign during follow-up; and retreatment of the index aneurysm at any time.

\section{Statistical Analyses}

Blinded data were to be examined at prespecified intervals by an independent Data Safety and Monitoring Committee (DSMC), composed of an interventional neuroradiologist, a statistician, and an ethicist. Means, standard deviations, medians, and ranges are presented for quantitative variables and frequency tables for categorical variables. Three groups of patients were analyzed as registered: standard management (randomly allocated), flow diversion (randomly allocated), and "registry" (pa- 


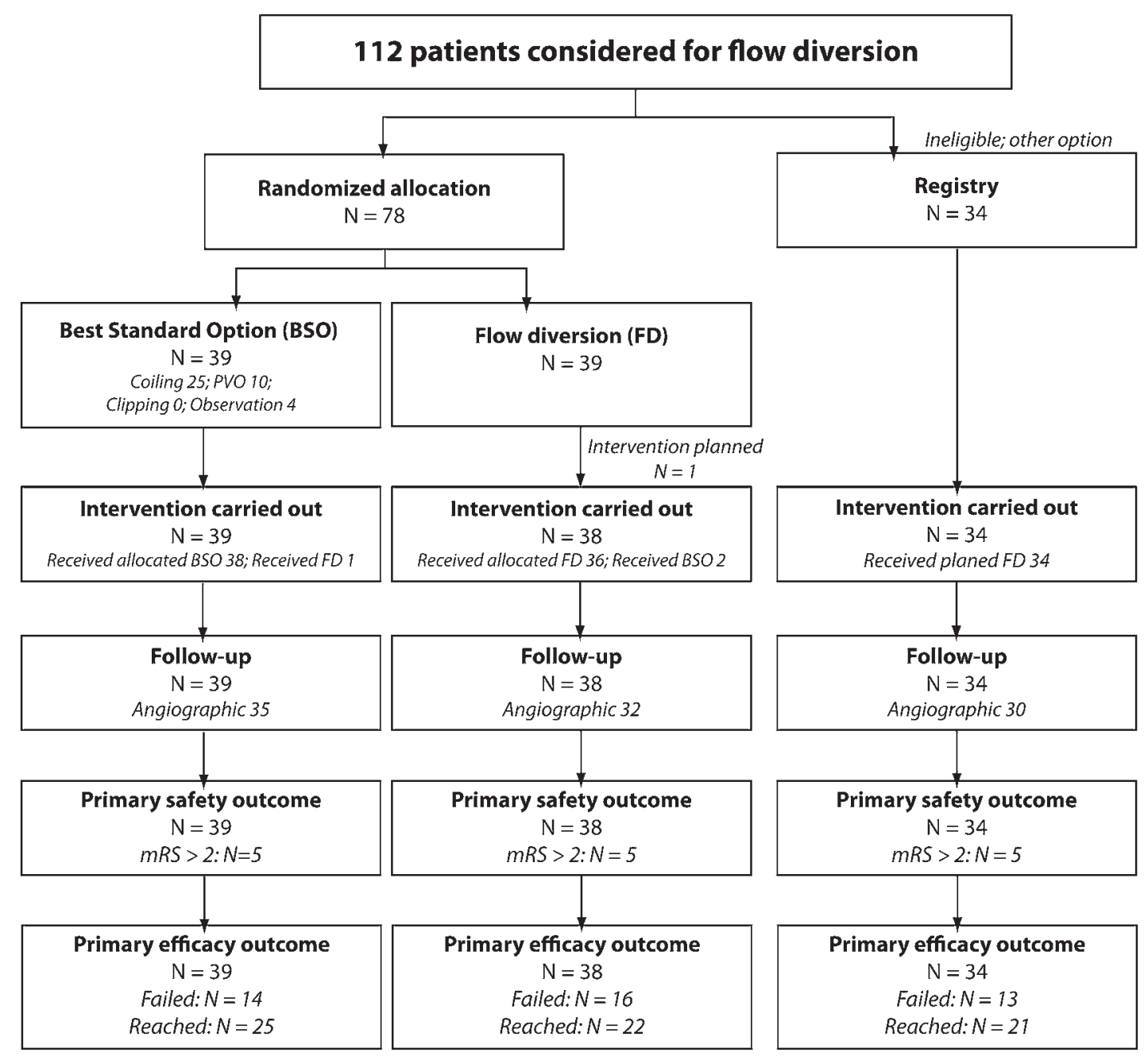

FIG. 1. Flow diagram of the clinical trial.

tients deemed ineligible for other management options). A fourth group, including all patients who were allocated or received flow diversion at any time, was predefined for the safety analyses of the pilot phase ("any flow diverter"). Treatment safety and efficacy were determined by inspecting results (intent-to-treat) tabulated according to treatment groups. Ninety-five percent confidence intervals (CIs) with continuity correction are provided for primary and secondary outcome measures. The primary safety outcome was adjudicated when the mRS score was $>2$, regardless of the cause. Failure to reach the primary efficacy endpoint was adjudicated in cases of death or dependency, treatment failure, retreatment during followup, or recurrent or enlarging aneurysm on angiography at 3-12 months. Operator-assessed angiographic results were categorized as complete/near-complete occlusions, residual/recurrent aneurysms, immediate failures, or not available. Subgroup analyses were predefined according to aneurysm location (proximal carotid artery [cavernous to the superior hypophyseal segment], other anterior circulation, and posterior circulation aneurysms) and according to best standard management options.

\section{Roles of the Funding Source}

The trial was sponsored by the Centre Hospitalier de l'Université de Montréal. The sponsor had no part in study design, data collection, analysis, or reporting, and no access to the data or source documents. The corresponding author had full access to all the data in the study and had final responsibility for the decision to submit for publication. There was no funding source for this study.

\section{Results}

The number of patients who were registered, randomly assigned, received intended treatment, and were analyzed for outcomes are shown in the trial profile (Fig. 1). Of 112 registered patients between May 2, 2011, and February 25, 2015, 34 deemed ineligible for standard options received flow diversion. Seventy-eight patients were randomized: 39 to flow diversion, and 39 to standard treatment. One patient (in the flow diversion arm) has yet to receive any intervention. Two patients randomly allocated to flow diversion initially received standard treatment, while 1 patient allocated to standard treatment initially received flow diversion. 
TABLE 1. Characteristics of the patients and aneurysms

\begin{tabular}{|c|c|c|c|c|}
\hline \multirow[b]{2}{*}{ Characteristic } & \multicolumn{2}{|c|}{ Randomization } & \multirow[b]{2}{*}{$\begin{array}{l}\text { Registry } \\
(n=34)\end{array}$} & \multirow[b]{2}{*}{$\begin{array}{l}\text { Any Flow Diverte } \\
\qquad(\mathrm{n}=76)\end{array}$} \\
\hline & $\begin{array}{c}\text { BSO } \\
(n=39)\end{array}$ & $\begin{array}{l}\text { Flow Diversion } \\
\qquad(\mathrm{n}=39)\end{array}$ & & \\
\hline Mean age \pm SD (yrs) & $57 \pm 11$ & $59 \pm 12$ & $58 \pm 13$ & $58 \pm 13$ \\
\hline No. of females (\%) & $34(87.2)$ & $32(82.1)$ & $25(73.5)$ & $59(77.6)$ \\
\hline \multicolumn{5}{|l|}{ Presentation (\%) } \\
\hline Asymptomatic & $20(51.3)$ & $20(51.3)$ & $17(50.0)$ & $38(50.0)$ \\
\hline Mass effect & $16(41.0)$ & $18(46.2)$ & $16(47.1)$ & $36(47.4)$ \\
\hline $\mathrm{SAH}$ & $3(7.7)$ & $1(2.6)$ & $1(2.9)$ & $2(2.6)$ \\
\hline \multicolumn{5}{|l|}{ Aneurysm size (mm) } \\
\hline Mean \pm SD & $16 \pm 11$ & $16 \pm 12$ & $19 \pm 13$ & $17 \pm 12$ \\
\hline Median (range) & $12(3-51)$ & $12(3-56)$ & $15(2-60)$ & $15(2-60)$ \\
\hline$>10 \mathrm{~mm}$ & $24(61.5 \%)$ & $23(59.0 \%)$ & $26(76.5 \%)$ & $52(68.4 \%)$ \\
\hline \multicolumn{5}{|l|}{ Aneurysm neck (mm) } \\
\hline Median (range) & $5(2-10)$ & $5(2-14)$ & $6(2-16)$ & $5(2-16)$ \\
\hline Undefined & $12(30.8 \%)$ & $15(38.5 \%)$ & $21(61.8 \%)$ & $39(51.3 \%)$ \\
\hline \multicolumn{5}{|l|}{ Location (\%) } \\
\hline Proximal carotid & $28(71.8)$ & $26(66.7)$ & $22(64.7)$ & $50(65.8)$ \\
\hline Other anterior & $4(10.3)$ & $6(15.4)$ & $7(20.6)$ & $13(17.1)$ \\
\hline Posterior circulation & $7(17.9)$ & $7(17.9)$ & $5(14.7)$ & $13(17.1)$ \\
\hline
\end{tabular}

SAH = subarachnoid hemorrhage.

The DSMC recommended temporary interruption of randomization in June 2014, while unblinded data were examined. The trial was restarted in August 2014 with a warning: flow diversion was to be used with caution until the results of the first 100 randomized patients would become available. In February 2015, the Steering Committee was notified of additional serious adverse events and that a prespecified safety boundary had been crossed.

The primary efficacy outcome and the safety data are available for 111 patients. Patients and aneurysms are described in Table 1. A single angiographic image of each case is provided in the Supplemental Data. The best standard option (BSO) selected at the time of randomization was coil embolization (with or without stent placement) in 25 patients, $\mathrm{PVO}$ in 10 patients, and observation in 4 patients (Fig. 1). Surgical clipping was not selected as the BSO for any patient. Patients allocated to flow diversion or treated in the registry were initially treated with a single flow diverter $(n=56)$ or 2 devices $(n=15)$, for a total of 47 Silk devices (Balt Extrusion) and 38 Pipeline Embolization devices (ev3). Clinical results are summarized in Table 2. Overall, 10 patients died, 5 had an mRS score $>2$ (Table 3 ), and $43(38.7 \%$ ) of 111 patients (95\% CI $29.8 \%-48.5 \%)$ failed to reach the primary efficacy endpoint (adjudicated as $\mathrm{mRS}$ score $>2, \mathrm{n}=15$; and 10 failures, 5 retreatments, and 13 recurrent aneurysms at follow-up). The mean duration of angiographic follow-up was $9.8 \pm 3.9$ months for patients randomly allocated to BSO $(n=35), 8.3 \pm 5.6$ months for those randomly allocated to flow diversion $(n=32)$, and $16.3 \pm 17.8$ months for those treated with flow diversion within the registry $(\mathrm{n}=30)$.

Twelve (16.0\%) of 75 patients (95\% CI 8.9\%-26.7\%) who received flow diversion at any time were dead $(\mathrm{n}=$ $8)$ or dependent $(n=4)$ at 3 months or more. Treatmentrelated death or dependency related to flow diversion $(n=$ 8 overall) occurred as a result of procedural complications ( $\mathrm{n}=2$, including device migration $[\mathrm{n}=1]$ and arterial rupture $[n=1])$, delayed aneurysmal ruptures $(n=2)$, hemorrhage at a distance from the aneurysm $(n=1)$, and unexpected delayed PVOs $(n=3)$. None of these poor outcomes were related to resistance to platelet inhibition (Table 3). Thirty-one (41.3\%) of 75 patients (95\% CI 30.3\%-53.3\%) failed to reach the primary efficacy outcome (mRS score $>2, \mathrm{n}=12$; and 8 failures, 3 retreatment, 8 residual aneurysms).

Morbidity or mortality occurred in $5(13.2 \%)$ of 38 patients randomly allocated to flow diversion (95\% CI $5.0 \%-28.9 \%)$ and in $5(12.8 \%)$ of 39 patients allocated to standard treatment (95\% CI 4.8\%-28.2\%). Two patients in the control group died or were dependent from flow diversion-related complications (delayed basilar thrombosis in a patient with 2 giant aneurysms; 1 delayed parenchymal hematoma with flow diversion carried out after failure of standard management).

Sixteen (42.1\%) of 38 patients (95\% CI $26.7 \%-59.1 \%)$ randomly allocated to flow diversion failed to reach the primary outcome, compared with 14 (35.9\%) of 39 patients allocated to standard treatment (95\% CI 21.7\%-52.9\%).

Predefined subgroups of interest are shown in Tables 4-5. Four $(8.0 \%)$ of 50 patients (95\% CI $2.6 \%-20.1 \%$ ) with proximal carotid aneurysms treated by flow diversion at any time were dead or dependent. Eleven (42.3\%) of 26 patients with proximal carotid aneurysms randomly allocated to flow diversion (95\% CI 24.0\%-62.8\%) failed to reach the primary efficacy outcome, as compared with 
TABLE 2. Primary safety and efficacy outcomes in all patients

\begin{tabular}{|c|c|c|c|c|c|c|c|c|}
\hline & \multicolumn{4}{|c|}{ Randomization } & \multirow{2}{*}{\multicolumn{2}{|c|}{ Registry $(n=34)$}} & \multirow{2}{*}{\multicolumn{2}{|c|}{ Any Flow Diverter $(n=75)$}} \\
\hline & \multicolumn{2}{|c|}{ BSO (n = 39) } & \multicolumn{2}{|c|}{ Flow Diversion $(n=38)$} & & & & \\
\hline & $n(\%)$ & $95 \% \mathrm{Cl}(\%)$ & $\mathrm{n}(\%)$ & $95 \% \mathrm{Cl}(\%)$ & $n(\%)$ & $95 \% \mathrm{Cl}(\%)$ & $\mathrm{n}(\%)$ & $95 \% \mathrm{Cl}(\%)$ \\
\hline \multicolumn{9}{|l|}{ Death } \\
\hline Related & $2(5.1)$ & $0.9-18.6$ & $2(5.3)$ & $0.9-19.1$ & $4(11.8)$ & $3.8-28.4$ & $7(9.3)$ & $4.2-18.9$ \\
\hline Unrelated & $1(2.6)$ & $0.1-15.1$ & $0(0.0)$ & $0-11.4$ & $1(2.9)$ & $0.2-17.1$ & $1(1.3)$ & $0.1-8.2$ \\
\hline Total & $3(7.7)$ & $2.0-22.0$ & $2(5.3)$ & $0.9-19.1$ & $5(14.7)$ & $5.5-31.8$ & $8(10.7)$ & $5.1-20.5$ \\
\hline mRS score 3-5 & $2(5.1)$ & $0.9-18.6$ & $3(7.9)$ & $2.1-22.5$ & $0(0.0)$ & $0-12.6$ & $4(5.3)$ & $1.7-13.8$ \\
\hline Primary safety outcome & $5(12.8)$ & $4.8-28.2$ & $5(13.2)$ & $5.0-28.9$ & $5(14.7)$ & $5.5-31.8$ & $12(16.0)$ & $8.9-26.7$ \\
\hline Any stroke & $4(10.3)$ & $3.3-25.2$ & $5(13.2)$ & $5.0-28.9$ & $2(5.9)$ & $1.0-21.1$ & $7(9.3)$ & $4.2-18.9$ \\
\hline Any other SAE or complication & $4(10.3)$ & $3.3-25.2$ & $11(28.9)$ & $16.0-46.1$ & $6(17.6)$ & $7.4-35.2$ & $17(22.7)$ & $14.1-34.1$ \\
\hline No complications & $26(66.7)$ & $49.7-80.4$ & $17(44.7)$ & $29.0-61.5$ & $21(61.8)$ & $43.6-77.3$ & $39(52.0)$ & $40.2-63.6$ \\
\hline \multicolumn{9}{|l|}{ Angiographic results } \\
\hline Immediate failure & $3(7.7)$ & $2.0-22.0$ & $8(21.1)$ & $10.1-37.8$ & $1(2.9)$ & $0.2-17.1$ & $9(12.0)$ & $6.0-22.1$ \\
\hline Residual aneurysm & $8(20.5)$ & $9.9-36.9$ & $7(18.4)$ & $8.3-34.9$ & $10(29.4)$ & $15.7-47.7$ & $17(22.7)$ & $14.1-34.1$ \\
\hline Residual neck & $7(17.9)$ & $8.1-34.1$ & $1(2.6)$ & $0.1-15.4$ & $0(0.0)$ & $0-12.6$ & $1(1.3)$ & $0.1-8.2$ \\
\hline Complete occlusion & $20(51.3)$ & $35.0-67.3$ & $21(55.3)$ & $38.5-71.0$ & $21(61.8)$ & $43.6-77.3$ & $44(58.7)$ & $46.7-69.7$ \\
\hline Data not available & $1(2.6)$ & $0.1-15.1$ & $1(2.6)$ & $0.1-15.4$ & $2(5.9)$ & $1.0-21.1$ & $4(5.3)$ & 1.7-13.8 \\
\hline \multicolumn{9}{|l|}{ Primary efficacy endpoint } \\
\hline Failed to reach primary endpoint & $14(35.9)$ & $21.7-52.9$ & $16(42.1)$ & $26.7-59.1$ & $13(38.2)$ & $22.7-56.4$ & $31(41.3)$ & $30.3-53.3$ \\
\hline Reached primary endpoint & $25(64.1)$ & $47.2-78.3$ & $22(57.9)$ & $40.9-73.3$ & $21(61.8)$ & $43.6-77.3$ & $44(58.7)$ & $46.7-69.7$ \\
\hline
\end{tabular}

SAE = serious adverse event.

Values outside the $95 \% \mathrm{Cl}$ are not plausible at a $5 \%$ significant level.

$10(35.7 \%)$ of 28 patients (95\% CI 19.3\%-55.9\%) allocated to standard treatment (Table 4).

Six (46.2\%) of 13 patients (95\% CI 20.4\%-73.9\%) with posterior circulation aneurysms treated by flow diversion (at any time) were dead or dependent. Of 13 patients randomly allocated to flow diversion $(n=6)$ or standard treatment $(n=7), 6$ were dead or dependent, 3 in each arm.

Of 51 patients eligible for coiling/stent-coiling, 2 (8.0\%) of 25 allocated to flow diversion (95\% CI 1.4\%-27.5\%) were dead or dependent, as compared with $0(0 \%)$ of 26 who were allocated to coiling (95\% CI $0.0 \%-16.2 \%)$. Nine patients $(36.0 \%)$ allocated to flow diversion $(95 \%$ CI $18.7 \%-57.4 \%$ ) failed to reach the primary outcome, as compared with 7 patients $(26.9 \%)$ who were allocated to coil embolization (95\% CI 12.4\%-48.1\%; Table 5).

\section{Discussion}

In this study, flow diversion in 75 patients led to a 5.3\% rate of morbidity and a $10.7 \%$ rate of death. The efficacy of flow diversion in patients eligible for other management options was below expectations: the 95\% CI of the proportion of flow-diverted patients failing to reach the primary efficacy outcome $(30.3 \%-53.3 \%)$ was significantly superior to the proportion hypothesized for the control group (25\%). Poor outcomes were adjudicated because of immediate treatment failures, serious adverse events with dependency, progressive neurological deficits, or retreatments (endovascular or surgical) in $12(31.6 \%)$ of 38 patients (95\% CI $18.0 \%-48.8 \%)$; supposing all remaining aneurysms would become occluded with longer follow-up, the primary efficacy outcome would still remain well below expectations $(51.2 \%-82.0 \%)$.

The morbidity and mortality of patients treated with flow diversion in FIAT are high as compared with endovascular coiling trials..$^{17,18,24,32}$ Such comparisons are invalid, because patients and aneurysms differ. Aneurysms treated with flow diversion are typically larger, present more often with mass effect, and are more difficult to treat. Morbidity and mortality are also high when compared with initial registries examined for US FDA approval (both reported as $2.8 \%$ ), in which cases were restricted to patients with proximal carotid aneurysms, ${ }^{2}$ or to single-center case series that may include other locations, but that may be affected by publication bias..$^{1-4,6,13,21,25}$ In FIAT, morbidity and mortality were lower for proximal carotid aneurysms $(8.0 \%)$ than for posterior circulation aneurysms (46.2\%). A similar contrast between anterior and posterior circulation aneurysms was reported in systematic reviews of flow diversion case series and registries. ${ }^{1,3}$

Randomized comparisons are available for patients with aneurysms deemed eligible for both treatment arms: although the number of patients is small, safety outcomes were similar. Yet 2 unfavorable outcomes in the control group were related to flow diversion. Serious clinical events associated with flow diversion (device migration, delayed ruptures, hemorrhage unrelated to the aneurysm, and delayed PVOs) are concerning. If some complications may have been prevented by case selection, or after learning curves plateau, others occurred in an unpredictable fashion. Many occurred in complex clinical circumstances; some have been previously published.9,10,12 Poor 
TABLE 3. Poor clinical outcomes in all patients

\begin{tabular}{|c|c|c|c|c|c|}
\hline $\begin{array}{l}\text { Age (yrs), } \\
\quad \text { Sex }\end{array}$ & Aneurysm & $\begin{array}{l}\text { Allocated } \\
\text { Treatment }\end{array}$ & $\begin{array}{l}\mathrm{mRS} \\
\text { Score }\end{array}$ & $\begin{array}{c}\text { Days Elapsed } \\
\text { Since Target } \\
\text { Procedure }\end{array}$ & Details \\
\hline \multicolumn{6}{|c|}{ Flow diversion } \\
\hline $66, \mathrm{M}$ & 24-mm vertebral artery & Flow diversion* & 5 & 0 & Progressive mass effect (surgery) \\
\hline $56, \mathrm{~F}$ & 27-mm basilar bifurcation & Flow diversion & 5 & 95 & Progressive mass effect (surgery) \\
\hline $66, \mathrm{~F}$ & 27-mm superior cerebellar artery & Flow diversion & 5 & 30 & Progressive mass effect (surgery) \\
\hline $63, \mathrm{~F}$ & 20-mm middle cerebral artery & Flow diversion & 6 & 509 & $\begin{array}{l}\text { Periprocedural (3rd intervention on target aneurysm) } \\
\text { arterial rupture }\end{array}$ \\
\hline $75, M$ & 3-mm ruptured carotid artery & Flow diversion & 6 & 8 & Migration (carotid thrombosis) \\
\hline $70, \mathrm{~F}$ & 14-mm distal carotid artery & Registry & 6 & 357 & Delayed rupture \\
\hline $50, M$ & 25-mm fusiform basilar & Registry & 6 & 586 & Basilar thrombosis (4th intervention on target aneurysm) \\
\hline $82, \mathrm{~F}$ & 19-mm symptomatic cavernous artery & Registry & 6 & 225 & Pneumonia \\
\hline $73, \mathrm{~F}$ & 50-mm symptomatic cavernous artery & Registry & 6 & 8 & Aneurysmal rupture \\
\hline $76, \mathrm{M}$ & $24-\mathrm{mm}$ vertebrobasilar artery & Registry & 6 & 37 & Basilar thrombosis \\
\hline \multicolumn{6}{|c|}{ Standard options } \\
\hline $66, \mathrm{~F}$ & 20-mm symptomatic cavernous artery & Observation† & 5 & 36 & Parenchymal hematoma \\
\hline $58, \mathrm{M}$ & 50-mm basilar bifurcation & Coils \& PVO & 5 & 20 & Progressive mass effect (surgery) \\
\hline $17, \mathrm{M}$ & Bilat 30-mm vertebral artery & PVO† & 6 & 427 & Basilar thrombosis \\
\hline $38, \mathrm{M}$ & 8-mm dissecting vertebral artery & PVO & 6 & 1 & Periprocedural rebleeding \\
\hline $68, F$ & 16-mm symptomatic cavernous artery & PVO & 6 & 368 & Neoplasia \\
\hline
\end{tabular}

clinical outcomes following flow diversion of posterior circulation aneurysms have been reported, $, 11,20,26,28$ and these patients may fare poorly no matter which treatment is selected. Results of flow diversion were more encouraging for aneurysms amenable to coil embolization, particularly on the proximal carotid artery; however, the patients who were randomly allocated to standard treatment did at least as well.

The clinical introduction of surgical innovations raises intricate conceptual and practical problems related to research and care. ${ }^{8}$ The new treatment may be used in selected patients deemed "untreatable by other means." If this were truly the case, then randomized allocation would be impossible, and strictly speaking results could not be compared with that of other treatments. Any judgment regarding treatment safety and efficacy may then appear arbitrary. Yet, patients included in the FIAT registry had a $14.7 \%$ mortality rate $(95 \%$ CI $5.6 \%-31.8 \%)$. The criterion of "untreatability by other means" is vague and subjective; ${ }^{8}$ when examined in retrospect, few of the 34 patients of the registry were truly ineligible for other management options. Had conservative management been considered for aneurysms with a favorable evolution, such as cavernous aneurysms, or conversely for posterior circulation aneurysms associated with a poor evolution but where flow diversion did poorly, then none of the patients included in the registry truly had no other option and would not have met the criterion of "untreatability by other means." The subjectivity of the judgement regarding eligibility for alternative treatments impacts several aspects of the design and conduct of the trial, such as selection criteria, recruitment, the diversity of recruited patients, and results, which may vary according to the kind of patients included in the comparison.

FIAT was designed as a care trial. ${ }^{22}$ Care trials are inspired from Chalmers' notion that we should "randomize the first patient, until the best therapy is identified." ${ }^{5}$ Care trials may eventually provide a verdict regarding the hypothetical benefits of a promising yet unvalidated intervention. In the meantime, they regulate practice under uncertainty, because using innovative instead of standard care calls for special measures: while standard care can be prescribed, unvalidated care is offered as a $50 \%$ chance of getting the innovative treatment, and an equal $50 \%$ chance of getting standard care, in order to balance the risks of receiving the inferior treatment, which is, for the time being, unknown. FIAT meets all of the characteristics of a care trial: inclusive selection criteria, no extra risk, no extra test, no extra cost, simple forms completed by care personnel, standard follow-up, and flexible care. ${ }^{22}$

The FIAT data showed worrisome complications from flow diversion, but no clear superiority of any treatment for aneurysms of any type. The sample sizes were small and a final verdict would be premature. However, the burden of proof remains on flow diversion. Flow diversion may be more prudently offered within a trial that makes it transparent that we are proposing a novel treatment under investigation, particularly when standard management options are possible.

Results of ongoing trials are normally concealed from clinicians, to prevent jumping to conclusions and interfering with enrollment. When there are concerns regarding the safety of participants, the trial is stopped, and patients are no longer exposed to experimental therapy. With flow 
TABLE 4. Primary safety and efficacy outcomes in patients with proximal carotid aneurysms

\begin{tabular}{|c|c|c|c|c|}
\hline \multirow[b]{2}{*}{ Variable } & \multicolumn{2}{|c|}{ Randomization } & \multirow[b]{2}{*}{$\begin{array}{l}\text { Registry } \\
(n=22)\end{array}$} & \multirow{2}{*}{$\begin{array}{c}\text { Any } \\
\text { Flow } \\
\text { Diverter } \\
(n=50)\end{array}$} \\
\hline & $\begin{array}{c}\text { BSO } \\
(n=28)\end{array}$ & $\begin{array}{c}\text { Flow } \\
\text { Diversion } \\
(n=26)\end{array}$ & & \\
\hline \multicolumn{5}{|l|}{ Deaths } \\
\hline Related & $0(0.0)$ & $1(3.8)$ & $1(4.5)$ & $2(4.0)$ \\
\hline Unrelated & $1(3.6)$ & $0(0.0)$ & $1(4.5)$ & $1(2.0)$ \\
\hline Total & $1(3.6)$ & $1(3.8)$ & $2(9.1)$ & $3(6.0)$ \\
\hline mRS score $3-5$ & $1(3.6)$ & $0(0.0)$ & $0(0.0)$ & $1(2.0)$ \\
\hline Primary safety outcome & $2(7.1)$ & $1(3.8)$ & $2(9.1)$ & $4(8.0)$ \\
\hline Any stroke & $3(10.7)$ & $2(7.7)$ & $1(4.5)$ & $3(6.0)$ \\
\hline $\begin{array}{l}\text { Any other SAE or com- } \\
\text { plication }\end{array}$ & $4(14.3)$ & $10(38.5)$ & $4(18.2)$ & $14(28.0)$ \\
\hline No complication & $19(67.9)$ & $13(50.0)$ & $15(68.2)$ & $29(58.0)$ \\
\hline \multicolumn{5}{|l|}{ Angiographic results } \\
\hline Immediate failure & $2(7.1)$ & $7(26.9)$ & $1(4.5)$ & $8(16.0)$ \\
\hline Residual aneurysm & $6(21.4)$ & $3(11.5)$ & $3(13.6)$ & $6(12.0)$ \\
\hline Residual neck & $4(14.3)$ & $1(3.8)$ & $0(0.0)$ & $1(2.0)$ \\
\hline Complete occlusion & $15(53.6)$ & $14(53.8)$ & $17(77.3)$ & $32(64.0)$ \\
\hline Data not available & $1(3.6)$ & $1(3.8)$ & $1(4.5)$ & $3(6.0)$ \\
\hline \multicolumn{5}{|l|}{ Primary efficacy endpoint } \\
\hline $\begin{array}{c}\text { Failed to reach pri- } \\
\text { mary endpoint }\end{array}$ & $10(35.7)$ & $11(42.3)$ & $5(22.7)$ & $17(34.0)$ \\
\hline $\begin{array}{l}\text { Reached primary } \\
\text { endpoint }\end{array}$ & $18(64.3)$ & $15(57.7)$ & $17(77.3)$ & $33(66.0)$ \\
\hline
\end{tabular}

All data in the table given as value (\%).

diversion, circumstances differ. Regulatory agencies have not required that new devices be shown to improve outcomes in randomized trials, and flow diverters remain available. Furthermore, flow diversion has been shown to be capable of curing difficult giant aneurysms while preserving the parent vessel. The trial was designed as a way to introduce the innovation in the care of patients with difficult aneurysms. Stopping the trial early is a difficult decision, ${ }^{27}$ particularly in this context: if flow diversion turns out to be the best treatment for some patients in the future, until better clinical outcomes are shown, the safest way to offer flow diversion may still be within a trial. Other trials on flow diversion have been designed. ${ }^{29,30}$ To avoid putting patients at unnecessary risk and to not delay the dissemination of important information, the steering committee chose to inform clinicians and future patients that the risks of flow diversion may not be as low and the efficacy may not be as high as the current nonrandomized studies in the literature suggest. In December 2014, the protocol was modified to encourage the use of flow diversion only as a randomized option, by proposing pre-randomization. ${ }^{34}$ The trial hypotheses need to be adjusted given the present data. We estimate that if there are reasons to believe that flow diversion may be more likely to be safe and effective with certain aneurysm locations, such as proximal carotid aneurysms, as compared with other locations, large trials (in the range of 600 patients) will be necessary to demon-
TABLE 5. Primary safety and efficacy outcomes in patients eligible for coil embolization or stent-coil embolization

\begin{tabular}{lcc}
\hline \multicolumn{1}{c}{ Variable } & \multicolumn{2}{c}{ Randomization } \\
\cline { 2 - 3 } & $\begin{array}{c}\text { Coiling or } \\
\text { Stent-Coiling } \\
(\mathrm{n}=26)\end{array}$ & $\begin{array}{c}\text { Flow } \\
\text { Diversion } \\
(\mathrm{n}=25)\end{array}$ \\
\hline Deaths & $0(0.0)$ & $1(4.0)$ \\
\hline mRS score 3-5 & $0(0.0)$ & $1(4.0)$ \\
\hline Primary safety outcome & $0(0.0)$ & $2(8.0)$ \\
\hline Any stroke & $1(3.8)$ & $2(8.0)$ \\
\hline Any other SAE or complication & $3(11.5)$ & $8(32.0)$ \\
\hline No complication & $22(84.6)$ & $13(52.0)$ \\
\hline Angiographic results & $1(3.8)$ & $4(16.0)$ \\
\hline Immediate failure & $6(23.1)$ & $4(16.0)$ \\
\hline Residual aneurysm & $7(26.9)$ & $0(0.0)$ \\
\hline Residual neck & $12(46.2)$ & $16(64.0)$ \\
\hline Occlusion & $0(0.0)$ & $1(4.0)$ \\
\hline Data not available & & \\
\hline Primary efficacy endpoint & $7(26.9)$ & $9(36.0)$ \\
\hline Failed to reach primary endpoint & $19(73.1)$ & $16(64.0)$ \\
\hline Reached primary endpoint & &
\end{tabular}

All data in the table given as value (\%).

strate a clinical benefit because standard care is likely to be as safe and effective for those same patients. ${ }^{24}$

There are limitations to this study. Only 3 centers participated, limiting the generalizability of results. The allinclusive nature of the FIAT trial and registry is consistent with the concept of using a care trial to offer an innovative procedure while simultaneously protecting patients from learning curves, or from the premature clinical adoption of unvalidated care that may turn out to be less safe or effective than standard therapy. An aneurysm "for which flow diversion is considered a promising treatment" is a vague definition that may be interpreted differently from one clinician to another. In addition, the trial was prematurely halted and the number of patients was small; no formal statistical testing was performed because of the exploratory nature of the study; outcome assessment was not blinded and angiographic results were not evaluated by a core laboratory; and the follow-up period was short. Flowdiverted aneurysms may become occluded in a delayed fashion, while recurrences after coil embolization may only become apparent with long-term follow-up $;^{15}$ thus, the potential benefits of flow diversion may be revealed only in the long term. Centers and operators were not selected on the basis of prior experience. As discussed above, the introduction of an innovative procedure involves entering uncertain territory, which may expose patients to physician learning curves regarding indications and procedural technique. The best way to protect patients during this period of uncertainty is to propose randomized allocation between the innovative procedure and the standard procedure that would have been offered prior to the introduction of the innovative treatment. 


\section{Conclusions}

In the FIAT study, flow diversion was not as safe and effective as initially hypothesized. More randomized trials are necessary to determine the role of flow diversion in the management of patients with intracranial aneurysms.

\section{References}

1. Arrese I, Sarabia R, Pintado R, Delgado-Rodriguez M: Flow-diverter devices for intracranial aneurysms: systematic review and meta-analysis. Neurosurgery 73:193-200, 2013

2. Becske T, Kallmes DF, Saatci I, McDougall CG, Szikora I, Lanzino G, et al: Pipeline for uncoilable or failed aneurysms: results from a multicenter clinical trial. Radiology 267:858868,2013

3. Brinjikji W, Murad MH, Lanzino G, Cloft HJ, Kallmes DF: Endovascular treatment of intracranial aneurysms with flow diverters: a meta-analysis. Stroke 44:442-447, 2013

4. Burrows AM, Cloft H, Kallmes DF, Lanzino G: Periprocedural and mid-term technical and clinical events after flow diversion for intracranial aneurysms. J Neurointerv Surg 7:646-651, 2015

5. Chalmers TC: Randomize the first patient. N Engl J Med 296:107, 1977 (Letter)

6. Chalouhi N, Starke RM, Yang S, Bovenzi CD, Tjoumakaris $S$, Hasan D, et al: Extending the indications of flow diversion to small, unruptured, saccular aneurysms of the anterior circulation. Stroke 45:54-58, 2014

7. Chalouhi N, Tjoumakaris S, Starke RM, Gonzalez LF, Randazzo C, Hasan D, et al: Comparison of flow diversion and coiling in large unruptured intracranial saccular aneurysms. Stroke 44:2150-2154, 2013

8. Darsaut TE, Gentric JC, McDougall CM, Gevry G, Roy D, Weill A, et al: Uncertainty and agreement regarding the role of flow diversion in the management of difficult aneurysms. AJNR Am J Neuroradiol 36:930-936, 2015

9. Darsaut TE, Rayner-Hartley E, Makoyeva A, Salazkin I, Berthelet F, Raymond J: Aneurysm rupture after endovascular flow diversion: the possible role of persistent flows through the transition zone associated with device deformation. Interv Neuroradiol 19:180-185, 2013

10. Estrade L, Makoyeva A, Darsaut TE, Ghostine J, Kouznetsov E, Salazkin I, et al: In vitro reproduction of device deformation leading to thrombotic complications and failure of flow diversion. Interv Neuroradiol 19:432-437, 2013

11. Fargen KM, Velat GJ, Lawson MF, Mocco J, Hoh BL: Review of reported complications associated with the Pipeline Embolization Device. World Neurosurg 77:403-404, 2012

12. Gentric JC, Fahed R, Darsaut TE, Salazkin I, Roy D, Raymond J: Fatal arterial rupture during angioplasty of a flow diverter in a recurrent, previously Y-stented giant MCA bifurcation aneurysm. Interv Neuroradiol 22:278-286, 2016

13. Kühn AL, Hou SY, Perras M, Brooks C, Gounis MJ, Wakhloo AK, et al: Flow diverter stents for unruptured saccular anterior circulation perforating artery aneurysms: safety, efficacy, and short-term follow-up. J Neurointerv Surg 7:634-640, 2015

14. Lanzino G, Crobeddu E, Cloft HJ, Hanel R, Kallmes DF: Efficacy and safety of flow diversion for paraclinoid aneurysms: a matched-pair analysis compared with standard endovascular approaches. AJNR Am J Neuroradiol 33:2158-2161, 2012

15. Lecler A, Raymond J, Rodriguez-Régent C, Al Shareef F, Trystram D, Godon-Hardy S, et al: Intracranial aneurysms: recurrences more than 10 years after endovascular treatmenta prospective cohort study, systematic review, and metaanalysis. Radiology 277:173-180, 2015

16. Lin N, Brouillard AM, Keigher KM, Lopes DK, Binning
MJ, Liebman KM, et al: Utilization of Pipeline embolization device for treatment of ruptured intracranial aneurysms: US multicenter experience. J Neurointerv Surg 7:808-815, 2015

17. McDougall CG, Johnston SC, Gholkar A, Barnwell SL, Vazquez Suarez JC, Massó Romero J, et al: Bioactive versus bare platinum coils in the treatment of intracranial aneurysms: the MAPS (Matrix and Platinum Science) trial. AJNR Am J Neuroradiol 35:935-942, 2014

18. Molyneux AJ, Clarke A, Sneade M, Mehta Z, Coley S, Roy $\mathrm{D}$, et al: Cerecyte coil trial: angiographic outcomes of a prospective randomized trial comparing endovascular coiling of cerebral aneurysms with either cerecyte or bare platinum coils. Stroke 43:2544-2550, 2012

19. Nelson PK, Lylyk P, Szikora I, Wetzel SG, Wanke I, Fiorella D: The pipeline embolization device for the intracranial treatment of aneurysms trial. AJNR Am J Neuroradiol 32:34-40, 2011

20. Park MS, Albuquerque FC, Nanaszko M, Sanborn MR, Moon $\mathrm{K}$, Abla AA, et al: Critical assessment of complications associated with use of the Pipeline Embolization Device. J Neurointerv Surg 7:652-659, 2015

21. Pistocchi S, Blanc R, Bartolini B, Piotin M: Flow diverters at and beyond the level of the circle of Willis for the treatment of intracranial aneurysms. Stroke 43:1032-1038, 2012

22. Raymond J, Darsaut TE, Altman DG: Pragmatic trials can be designed as optimal medical care: principles and methods of care trials. J Clin Epidemiol 67:1150-1156, 2014

23. Raymond J, Darsaut TE, Guilbert F, Weill A, Roy D: Flow diversion in aneurysms trial: the design of the FIAT study. Interv Neuroradiol 17:147-153, 2011

24. Raymond J, Klink R, Chagnon M, Barnwell SL, Evans AJ, Mocco J, et al: Patients prone to recurrence after endovascular treatment: periprocedural results of the PRET randomized trial on large and recurrent aneurysms. AJNR Am J Neuroradiol 35:1667-1676, 2014

25. Saatci I, Yavuz K, Ozer C, Geyik S, Cekirge HS: Treatment of intracranial aneurysms using the pipeline flow-diverter embolization device: a single-center experience with longterm follow-up results. AJNR Am J Neuroradiol 33:14361446,2012

26. Siddiqui AH, Abla AA, Kan P, Dumont TM, Jahshan S, Britz $\mathrm{GW}$, et al: Panacea or problem: flow diverters in the treatment of symptomatic large or giant fusiform vertebrobasilar aneurysms. J Neurosurg 116:1258-1266, 2012

27. Stallard N, Whitehead J, Todd S, Whitehead A: Stopping rules for phase II studies. Br J Clin Pharmacol 51:523-529, 2001

28. Toth G, Bain M, Hussain MS, Moskowitz S, Masaryk T, Rasmussen $\mathrm{P}$, et al: Posterior circulation flow diversion: a singlecenter experience and literature review. J Neurointerv Surg 7:574-583, 2015

29. Turjman F, Levrier O, Combaz X, Bonafé A, Biondi A, Desal $\mathrm{H}$, et al: EVIDENCE trial: design of a phase 2, randomized, controlled, multicenter study comparing flow diversion and traditional endovascular strategy in unruptured saccular wide-necked intracranial aneurysms. Neuroradiology 57:49-54, 2015

30. Turk AS III, Martin RH, Fiorella D, Mocco J, Siddiqui A, Bonafe A: Flow diversion versus traditional endovascular coiling therapy: design of the prospective LARGE aneurysm randomized trial. AJNR Am J Neuroradiol 35:1341-1345, 2014

31. van Rooij WJ, Sluzewski M, van der Laak C: Flow diverters for unruptured internal carotid artery aneurysms: dangerous and not yet an alternative for conventional endovascular techniques. AJNR Am J Neuroradiol 34:3-4, 2013

32. White PM, Lewis SC, Gholkar A, Sellar RJ, Nahser H, Cognard C, et al: Hydrogel-coated coils versus bare plati- 
num coils for the endovascular treatment of intracranial aneurysms (HELPS): a randomised controlled trial. Lancet 377:1655-1662, 2011

33. Zanaty M, Chalouhi N, Tjoumakaris SI, Gonzalez LF, Rosenwasser R, Jabbour P: Flow diversion for complex middle cerebral artery aneurysms. Neuroradiology 56:381-387, 2014

34. Zelen M: Randomized consent designs for clinical trials: an update. Stat Med 9:645-656, 1990

\section{Disclosures}

Dr. Raymond is a principal investigator for the CURES Study (funded by the Canadian Institutes of Health Research, grant paid to his institution) and for the DELTA study (funded by Johnson \& Johnson, grant paid to his institution)

\section{Author Contributions}

Conception and design: Raymond, Darsaut. Acquisition of data: Raymond, Gentric, Darsaut, Iancu, Weill, Roy. Analysis and interpretation of data: Raymond, Gentric, Darsaut, Weill, Roy. Drafting the article: Raymond, Darsaut. Critically revising the article: all authors. Reviewed submitted version of manuscript: all authors. Approved the final version of the manuscript on behalf of all authors: Raymond. Statistical analysis: Chagnon. Study supervision: Raymond, Darsaut.

\section{Supplemental Information}

Online-Only Content

Supplemental material is available with the online version of the article.

Supplemental Data. https://thejns.org/doi/suppl/10.3171/2016. 4.JNS152662.

\section{Correspondence}

Jean Raymond, CHUM, Notre-Dame Hospital, Department of Radiology, 1560 Sherbrooke East, Pavilion Simard, Ste. Z12909, Montreal, QC H2L 4M1, Canada. email: jean.raymond@ umontreal.ca. 